Research Article

\title{
Forming Quality and Fatigue Behavior of Self-Piercing Riveted Joints of DP590 and AA6061 Plates
}

\author{
Yinglian Jia $\left(\mathbb{D}\right.$, Zhichao Huang $\mathbb{D}^{\mathrm{D}}$, Yongchao Zhang ${ }^{(\mathbb{D} \text {, and Fan Zhang }}$ \\ Key Laboratory for Conveyance and Equipment, Ministry of Education, East China Jiaotong University, \\ Nanchang 330013, China \\ Correspondence should be addressed to Zhichao Huang; hzc@ecjtu.edu.cn
}

Received 28 July 2021; Accepted 29 September 2021; Published 18 October 2021

Academic Editor: Davide Palumbo

Copyright (c) 2021 Yinglian Jia et al. This is an open access article distributed under the Creative Commons Attribution License, which permits unrestricted use, distribution, and reproduction in any medium, provided the original work is properly cited.

Two kinds of self-piercing riveted (SPR) joints were prepared with DP590 and AA6061 plates. The forming qualities of the joints were studied using the finite element method. The relationships between the fatigue life and failure forms of the joints with different upper plates were discussed. Finally, the failure mechanisms of the joints were analyzed. The results show that the maximum static tension of DA32 joints (with an upper plate of DP590) is significantly greater than that of the other kind, and the fatigue life of DA32 joints is always longer than that of AA40 joints when with a $2.0 \mathrm{~mm}$ thick AA6061 aluminum alloy upper plate under the same fatigue load. The failure mode of SPR joints changes obviously due to different upper plates, and the fatigue life of the joints can be effectively improved by reducing the microvibration wear.

\section{Introduction}

Due to the increasingly strict requirements of environmental protection and energy-saving, lightweight technology has drawn much attention in the development of the automobile industry. Together with lightweight materials (e.g., highstrength steels, aluminum alloys, and organic-inorganic composites) for automotive development $[1,2]$, lightweight connections designed for simple equipment and heterogeneous materials joints $[3,4]$ have become a hot point in recent years. Traditional mechanical joints (such as bolted joints) usually cause drilling holes in the connected parts, which not only make the connection process complicated but also affect the appearance quality and corrosion resistance of the connected parts [5]. Spot welding technology does not apply to the connection of light alloy or different materials [6]. As a new cold connection technology, selfpiercing riveting uses rivets to join the upper plate and lower plate under the effect of rivet die without piercing the connected lower plate. Through plastic deformation of the rivet leg and lower plate, a firm mechanical interlocking is formed between the lower plate and rivet leg $[7,8]$. Selfpiercing riveting connection technology can well solve the shortcomings mentioned above and can realise the effective connection between light alloy or different material parts [9]. At present, it has become one of the most important manufacturing processes for body board connections [10].

To develop self-piercing riveting technology in engineering, scholars have done much research from different perspectives. For instance, SPR tests [11, 12], simulation of self-piercing riveting process $[13,14]$, and static and dynamic performance tests of riveted joints [15-17] were carried out for achieving high performance and reasonable SPR joint structures, and research studies on the strength and failure performance of riveted joints from a microperspective $[18,19]$ for a deep understanding in mechanisms are carried out. In terms of the materials of SPR joints, researchers have studied the connection of the same metal materials [20], the connection of different metal materials $[21,22]$, and the connection of metal and composite materials $[23,24]$. However, the research on the fatigue performance and failure mechanism of the SPR joints between the dual-phase steel and the high-strength aluminum dissimilar material is relatively less. Up to now, some simple experiments were carried out on two different SPR joints of DP590 and AA6061, and the forming quality of SPR joints 
was only studied by experiments [25]. In this paper, the performance of SPR joints was studied experimentally and numerically in order to verify the variation trend of SPR joint forming quality. In addition, the mechanical properties of the joints were compared and analyzed by the tensile test and fatigue test. The sections of typical fatigue failure joints were observed by using the scanning electron microscope (SEM), and the relationship between fatigue failure form and failure mechanism was explored from the microscopic point of view.

\section{Experimental Procedure}

\subsection{Self-Piercing Riveting Test}

2.1.1. Preparation of the SPR Joints. The materials of plates are, respectively, DP590 and AA6061 in the self-piercing riveting test. The mechanical properties of these materials are listed in Table 1.

The self-piercing riveting test was carried out on the RV300023 self-piercing riveting machine of Henrob Company in the UK. The concave die is shown in Figure 1(a). Figure 1(b) shows the dimensions of the semihollow rivets. The rivet is made of $36 \mathrm{MnB} 4$ high-strength steel and is coated with zinc-tin alloy. All rivets used have the same head diameter and outside diameter of rivet legs, which were, respectively, $7.7 \mathrm{~mm}$ and $5.3 \mathrm{~mm}$. The hardness of rivets was $\mathrm{H} 4$ series. The mechanical behavior of the rivets is listed in Table 2. However, the length of the rivet was not same in the different SPR joints. Table 3 lists the rivet length of each group of SPR joints and various stack configurations.

The plates used in the test were cut along the rolling direction, and each was $135 \mathrm{~mm} \times 36 \mathrm{~mm}$ samples. All SPR joints are used by a single lap joint. The length of the lap area is $36 \mathrm{~mm}$. Moreover, details of plate assemblies are shown in Figure 1(c). All SPR joints were made that the riveting pressure is about $190 \mathrm{MPa}$. The test samples were prepared for each group as shown in Figure 1(c) and Table 2. The three joints in each group were used to observe the cross-sectional morphology of the joints by digital microscopy. The five joints were randomly taken out from each group for the tensile test, and others were used for the fatigue strength test.

2.1.2. Section Quality Analysis Test of the SPR Joints. The three groups of SPR joints were cut along the central axis of the joint, and the cross-sectional morphology of the joints was observed by using a digital microscope. Figure 2 is the schematic diagram of joints evaluation parameters. The mean values of the main evaluation parameters of DA32 and AA40 joints observed by using digital microscope are listed in Table 4.

2.2. Finite Element Simulation of the Self-Piercing Riveting Process. In the finite element simulation analysis of selfpiercing riveting, the (Mechanical joining) module of simufact.forming ${ }^{\mathrm{TM}}$ software is used to create the finite element model of forming self-piercing riveting, as shown in Figure 3.
The finite element model and relevant parameters required for the finite element simulation of self-piercing riveting are shown in Table 5.

The finite element simulation test is carried out according to the configuration mode of self-piercing riveting connection plates and the setting requirements of relevant parameters as shown in Table 3 and Figure 3. During the finite element simulation, the elastic-plastic body is divided into "Quadtree" cells with good mesh and boundary refinement functions. The termination condition of the selfpiercing riveted test is to set the minimum thickness of the lower plate when it is not punctured by the rivet (set as $0.1 \mathrm{~mm}$ here). The main evaluation parameters obtained from the simulation test are shown in Table 6. In order to distinguish from the evaluation parameters of the selfpiercing riveted test, the evaluation parameters of the results of finite element analysis are subscript $\mathrm{S}$ based on the original evaluation parameters.

\subsection{Mechanical Property Test}

2.3.1. Tensile Test. RGM-4030 microcomputer-controlled electronic universal material testing machine is used for the quasi-static tensile test. In order to avoid the deviation between the load axis and the center line of the test samples loaded, a spacer shall be placed at each gripping end of the test sample as shown in Figure 1(c). The size of the spacer was $36 \mathrm{~mm} \times 36 \mathrm{~mm}$. For each group of joints prepared, five test samples are randomly selected for the tensile test. Moreover, the tensile tests were performed with a constant speed of $2 \mathrm{~mm} / \mathrm{min}$ on the universal material testing machine. Two groups of SPR joints were subjected to tensile tests, respectively, and the load-displacement curves are shown in Figure 4.

To inspect the rationality of the tensile test data, the normal hypothesis tests were performed by Origin software. At the level of 5\%, the two groups of tensile test data follow significantly from the normal distributions. According to T-distribution, using the pivot variable method to estimate the interval, we can see that the mean value of the peak static load of each group of joints is valid within $95 \%$ confidence interval. Moreover, the maximum static mean load values of DA32 and AA40 joints are $9.18 \mathrm{kN}$ and $8.60 \mathrm{kN}$, respectively.

2.3.2. Fatigue Test. The fatigue test equipment is a QBG-50 microcomputer-controlled high-frequency fatigue test machine produced by Changchun Qianbang Test Equipment Co., Ltd. Sample DA32 and AA40 joints used for the fatigue test are the same batch used for the tensile test. The clamping method of the specimen for the fatigue test is the same as the tensile test.

The self-piercing riveted joints used in the automobile industry will face more complex and changeable load conditions, so the design of SPR joints should meet all kinds of needs from tensile strength to fatigue strength. Moreover, the load required for fatigue failure is usually smaller than that for static failure. The fatigue test parameters were based on the mean peak loads obtained from quasi-static tensile 
TABLE 1: Mechanical properties of DP590 plate and AA6061 plate.

\begin{tabular}{lcccc}
\hline Materials & Ultimate tensile strength $(\mathrm{MPa})$ & Yield strength $(\mathrm{MPa})$ & Young modulus $(\mathrm{GPa})$ & Elongation $(\%)$ \\
\hline DP590 & 520 & 275 & 200 & 25 \\
AA6061 & 315 & 205 & 68.6 & 12 \\
\hline
\end{tabular}

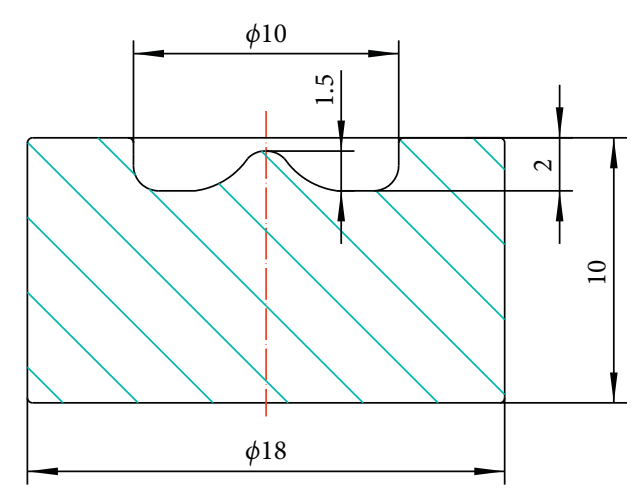

(a)

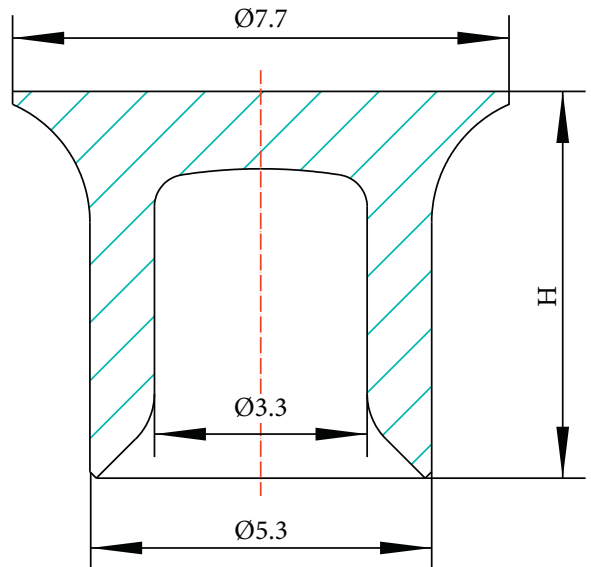

(b)

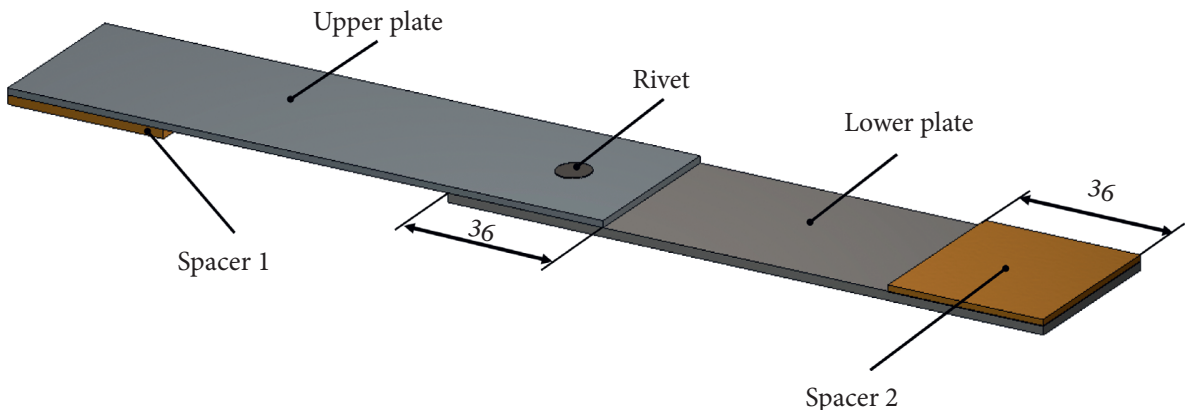

(c)

Figure 1: Dimensions of the rivets, the die, and the plates: (a) geometry and dimensions of the die; (b) geometry and dimensions of the rivets; (c) dimensions of plates and connection mode.

TABle 2: Mechanical properties of the rivet.

\begin{tabular}{lccc}
\hline Poisson's ratio & Yield strength $(\mathrm{MPa})$ & Young modulus $(\mathrm{GPa})$ & Compressive strength $(\mathrm{MPa})$ \\
\hline 0.3 & 1697 & 215 & 1605 \\
\hline
\end{tabular}

TABLE 3: Summary of various stack configurations.

\begin{tabular}{|c|c|c|c|c|c|c|}
\hline Joint ID & Upper $\mathrm{p}$ & ness & Lower $\mathrm{p}$ & ness & Joint stack (mm) & Rivet length (mm) \\
\hline DA32 & DP590 & 1.2 & AA6061 & 2.0 & 3.2 & 6 \\
\hline AA40 & AA6061 & 2.0 & AA6061 & 2.0 & 4.0 & 6.5 \\
\hline
\end{tabular}

tests. In the fatigue tests, a cyclic load of a sine wave with frequency $f=80 \mathrm{~Hz}$ was applied, where the load ratio was set as $R=0.1$. Six fatigue load levels in each group were selected to demonstrate the fatigue behavior of the SPR joints, and at least three specimens were tested at each load level. The termination of the fatigue test was based on the case that the fatigue cycle of the sample exceeds 2 million cycles or the sample has obvious cracks, whichever came first. The fatigue test data of two groups of joints were statistically analyzed by the Weibull distribution method [26]. The mean fatigue life and other statistical data of each specimen of two groups of joints are shown in Table 7. The AD in Table 7 is Anderson-Darling statistics, indicating the degree to which the measured data obey a specific distribution. The smaller the 


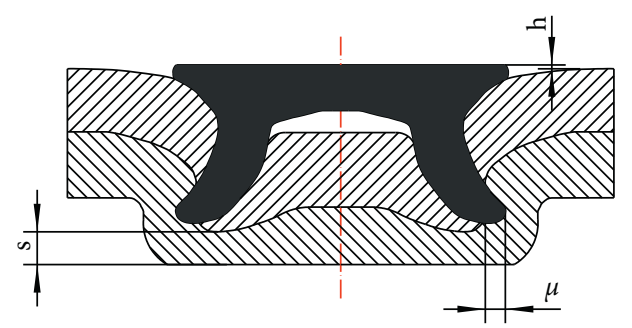

FIGURE 2: The sectional structure shape of each kind joint.

TABle 4: The main evaluation parameters of the joints obtained by the self-piercing riveting test.

\begin{tabular}{lccc}
\hline Joint ID & Self-locking length $u(\mathrm{~mm})$ & Rivet head height $h(\mathrm{~mm})$ & Minimum residual bottom thickness $s(\mathrm{~mm})$ \\
\hline DA32 & 0.9742 & -0.2046 & 0.9527 \\
AA40 & 0.7622 & -0.1950 & 0.5754 \\
\hline
\end{tabular}

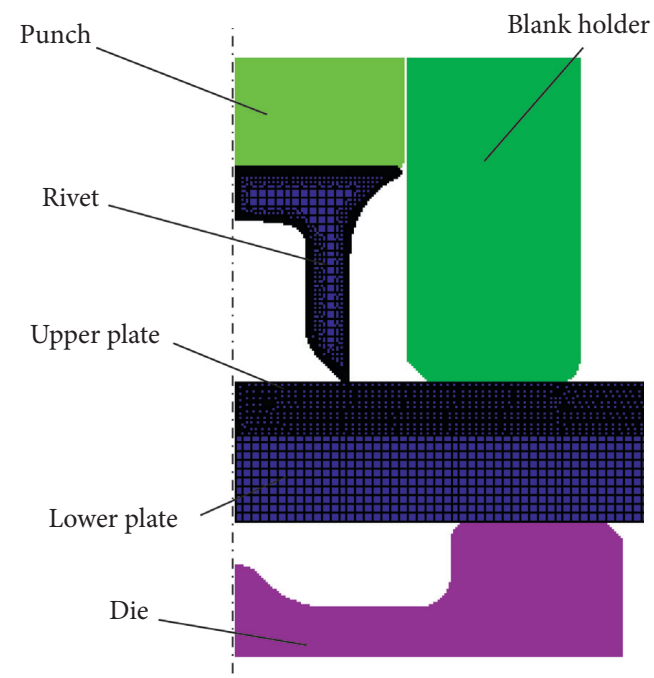

Figure 3: Finite element simulation.

TABLE 5: Finite element model and setting of related parameters.

\begin{tabular}{lc}
\hline Parameter name & Parameter value \\
\hline Upper plate, lower plate, and rivet & Elastic-plastic \\
Die, punch, and blank holder & Rigid \\
Friction & Combined \\
Velocity of hydraulic press & $20 \mathrm{~mm} / \mathrm{s}$ \\
Stiffness of die spring & $500 \mathrm{~N} / \mathrm{mm}$ \\
Initial force of spring & $2.0 \mathrm{kN}$ \\
Temperature of rivet, plate, and die & $20^{\circ} \mathrm{C}$ \\
Heat transfer coefficient to environment (HTC) & $50 \mathrm{~W} /\left(\mathrm{m}^{3} \cdot k\right)$ \\
\hline
\end{tabular}

TABLE 6: The main evaluation parameters of the joints obtained by finite element simulation.

\begin{tabular}{lccc}
\hline $\begin{array}{l}\text { Joint } \\
\text { ID }\end{array}$ & $\begin{array}{c}\text { Self-locking } \\
\text { length } u_{S}(\mathrm{~mm})\end{array}$ & $\begin{array}{c}\text { Rivet head } \\
\text { height } h_{S}(\mathrm{~mm})\end{array}$ & $\begin{array}{c}\text { Minimum residual } \\
\text { bottom thickness } \\
s_{S}(\mathrm{~mm})\end{array}$ \\
\hline DA32 & 1.263 & -0.186 & 0.227 \\
AA40 & 0.986 & -0.256 & 0.149 \\
\hline
\end{tabular}

statistic is, the better the distribution fits the data. The shape parameters describe the distribution of data and determine the shape of the distribution function. The scale parameter defines the position of the Weibull curve relative to the threshold.

\section{Results and Discussion}

3.1. Forming Quality Analysis of Self-Piercing Riveted Joints. Among the three evaluation parameters, the self-locking length is the most important index to determine the mechanical properties of the joints. So, the self-locking length of the joints is analyzed when comparing the forming quality of the joints. It can be seen from Table 4 and Table 6 that the self-locking length of DA32 joints is longer $(u=0.9742 \mathrm{~mm}$ and $\left.u_{s}=1.263 \mathrm{~mm}\right)$ than that of AA40 joint $(u=0.7622 \mathrm{~mm}$ and $u_{s}=0.986 \mathrm{~mm}$ ) in both self-piercing riveted test and finite element simulation analysis. According to the selfpiercing riveting quality evaluation parameters, the longer the self-locking length, the better the riveting quality of the SPR joints. Therefore, whether the self-piercing riveting test or finite element simulation of self-piercing riveting, it can be preliminarily judged that the self-piercing riveting quality of DA32 joints is better.

3.2. Analysis of the Fatigue Test Results. Due to the small sample size and large dispersion of fatigue test data, it is difficult to directly solve Weibull parameters. Thus, Mini$\mathrm{tab}^{\mathrm{TM}}$ software can be used to process the fatigue test data. It can be seen from Table 7 that the mean value of $95 \%$ confidence interval calculated by scale parameter $\beta$ is greater than that of life, which can be verified that the data obtained are reliable and effective by the fatigue test.

In order to study the fatigue characteristics of each group of joints, the least square method was used to fit the fatigue test data, and then the F-N curves were obtained [27, 28]. The fatigue load-life $(F-N)$ curves of DA32 and AA40 SPR joints were obtained, as shown in Figure 5. The fitting equation of two groups of SPR joints was, respectively, 


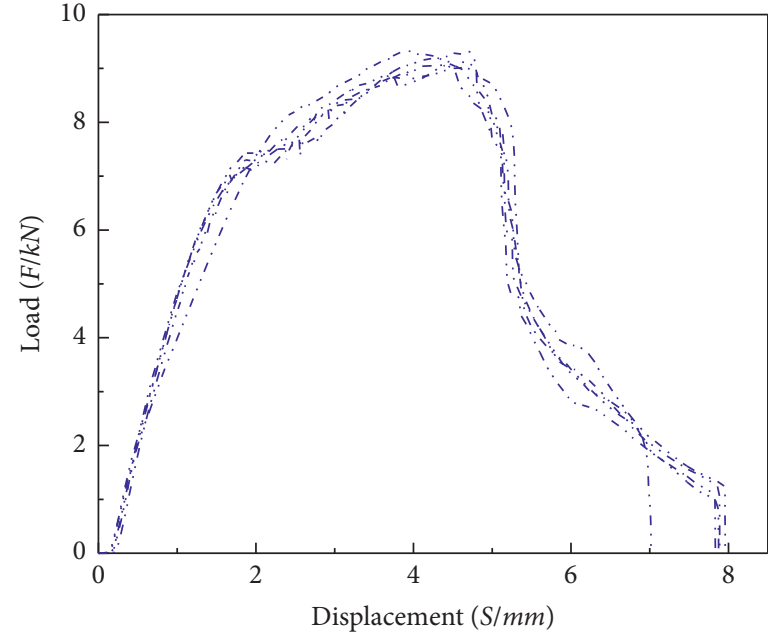

DA32 joint

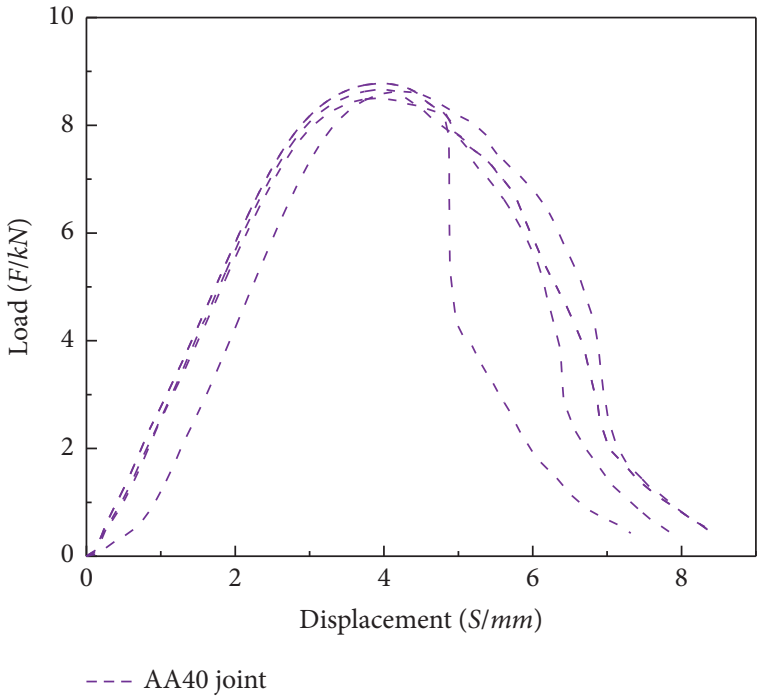

(b)

Figure 4: Load-displacement curves of two groups of joints: (a) DA32 joints; (b) AA40 joints.

TABLE 7: Fatigue life statistics of two groups of SPR joints.

\begin{tabular}{|c|c|c|c|c|c|c|c|c|c|c|c|c|}
\hline \multirow{2}{*}{$\begin{array}{l}\text { Joint ID } \\
\text { Load level }\end{array}$} & \multicolumn{6}{|c|}{ DA32 } & \multicolumn{6}{|c|}{ AA40 } \\
\hline & $70 \%$ & $60 \%$ & $50 \%$ & $40 \%$ & $30 \%$ & $19 \%$ & $70 \%$ & $60 \%$ & $50 \%$ & $40 \%$ & $30 \%$ & $27 \%$ \\
\hline Life mean & 17600 & 26100 & 50500 & 131033 & 427667 & 1271233 & 17400 & 39866 & 63467 & & 517367 & 1126600 \\
\hline $\mathrm{AD}$ & & & & & 0.402 & & 0.423 & 0.273 & 0.255 & & 0.495 & 0.253 \\
\hline Shape param & 12.22 & 8.756 & 7.661 & 7.062 & 8.694 & 3.653 & 5.204 & 4.390 & 9.401 & 3.730 & 6.821 & 9.227 \\
\hline Scale parameter $(\beta)$ & 18466 & 27580 & 53978 & 141194 & 455099 & 1413262 & 19050 & 40408 & 67047 & 159060 & 552920 & 1189077 \\
\hline
\end{tabular}

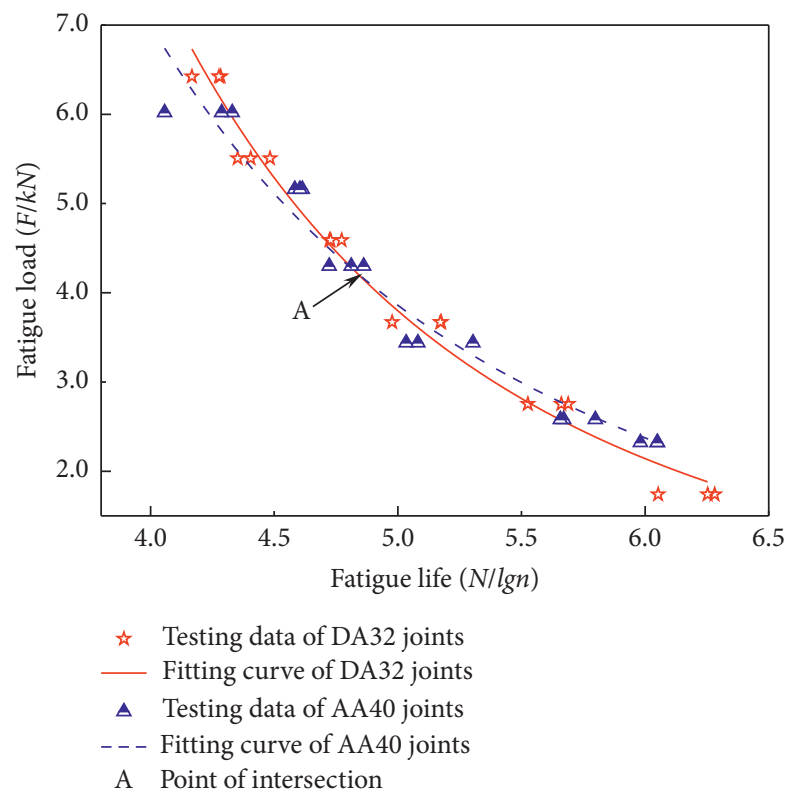

Figure 5: F-N curves of two groups of SPR joints.

$\lg N=8.0-4.41 \quad[\lg (F+0.85)] \quad$ and $\lg N=7.85-4.54 \quad[\ln$ $(F+0.30)]$. The Goodness of Fit refers to how well the regression line fits the observations. The statistic that measures the goodness of fit is the coefficient of determination (also known as the coefficient of determination) $R^{2}$. The maximum value of $R^{2}$ is 1 . The closer the value of $R^{2}$ is to 1 , the better the fit of the regression line to the observed value. Two groups of SPR joints of the value of $R^{2}$ were 0.98269 and 
0.96405 , so the fatigue load-life curves fitted by the test data were correct.

Figure 5 shows that the fatigue test data fitting two fatigue load-life curves of $\lg N=8.0-4.41[\lg (F+0.85)]$ and $\lg N=7.85-4.54[\ln (F+0.30)]$ intersect at point $A$ $\left(7.1335 \times 10^{4}, 4.1732 \times 10^{3}\right)$. The fatigue life at the junction is $7.1335 \times 10^{4}$ cycles, which is a $40 \%-50 \%$ load level of DA32 joints and AA40 joints. It can be seen that at a higher load level, the fatigue life of the DA32 joint is longer than that of AA40 joints under the same load.

\subsection{The Influence of the Upper Plate on Fatigue Failure Mode.} As can be seen from Figure 6(a), some samples were rivet fracture, others were lower plate fracture, and still others were rivet fracture and lower plate fracture simultaneously. Therefore, the fatigue failure forms of DA32 joints were diverse at different fatigue load levels.

The fatigue failure was only lower plate failure at the fatigue load level of $30 \%$ and $19 \%$. When the load level changes from $30 \%$ to $40 \%$, the fatigue failure mode was transferred from the fracture failure of the lower plate to the rivet fracture failure. When the load level increases to $70 \%$, the fatigue failure mode of all DA32 joints was rivet failure. In addition, the fracture failure of the lower plate gradually expanded from the middle part of the rivet to the direction of plate width and plate thickness in the mode of fatigue failure of DA32 joints, and finally the joint connection failed. At the lower fatigue load level, the rivet leg and the lower plate of the DA32 joint produce fretting wear under the action of a small variable load. In the self-locking area for the DA32 joints, the fatigue resistance of the lower plate aluminum alloy AA6061 was the weakest, so the lower plate aluminum alloy AA6061 became the weak part of the DA32 joints. Therefore, the fatigue failure mode at this load level was the fracture failure of the lower plate. With the increase in fatigue load level, the alternating shear stress of DA32 joint increases gradually. When the shear stress on the shear plane is greater than the allowable shear stress of rivet material, the rivet will be sheared. Therefore, the fatigue failure mode of the DA32 joints under the high load level was rivet fracture. When the load increases to a value, the fatigue life of DA32 joints is reduced under the action of a large variable load.

It can be seen from Figure 6(b) that the fatigue failure of this group of AA40 joints is the fracture failure of the lower plate, regardless of the test samples at any fatigue load level. During the fatigue test of all joints, the shear stress on the shear plane of AA40 joint rivets did not exceed the allowable shear stress of rivet material. Therefore, no rivet was cut in AA40 joints. According to the macroscopic fracture process of the joints, the rivet and the self-locking area of the lower plate fretted during the fatigue test. So, the fatigue crack was generated in the rivet area of the lower plate. As the test continued, the crack began to expand to one end of the lower plate, eventually leading to the fracture of the lower plate and the failure of the joint.

\subsection{Failure Mechanism of Joint}

3.4.1. Failure Mechanism of DA32 Joints. Figure 7(a) shows the macroscopic characteristics of rivet fracture of joint No. 5 for DA32 joints. An area of rivet fracture is selected as shown in Figure 7(a), and the observation results by SEM (scanning electron microscope) are shown in Figures 7 (b) and $7(\mathrm{c})$. As seen from the microscopic observation of the rivet in Figure 7(a), there is no obvious plastic deformation of the rivet. And it can be found that the morphology of this region shows the characteristics of fatigue stripe and river pattern in Figure 7(b). At a high-stress level, the fretting wear was severe between the rivet leg and the connecting plate. Fretting wear results in particle spalling on the surface of rivets, which led to the surface wear of rivet legs and the initiation of fatigue microcracks. With the increase in stress cycles, the fatigue crack of the joint rivet propagated gradually and eventually led to the fracture of the rivet [25]. So, many microfatigue cracks and particles are observed on the rivet leg in Figure 7(c).

The lower plate fracture of the DA32 group No. 5 sample was observed by SEM, as shown in Figure 8. From Figure 8 (a) of the macroscopic failure sample, it can be seen that there are massive black particles in $2 \#$. It can be seen that there are micropores and a large number of particles in this part from the microstructure of Figures 8(c) and 8(d). These particles were the wear debris formed by strong microvibration at the contact between rivet foot and lower plate under alternating force. In the local position of the contact surface, the wear debris gathered here to produce stress concentration, which led to the damage of the interface of the base metal and the formation of tiny cavities these microholes connected and expanded gradually under the action of alternating force. The stress at the crack tip will increase continuously, and new microholes will be generated simultaneously. The joint connection failed finally, so this part was the fatigue source area. The number and width of microcracks were very large, which was an obvious microscopic feature of the fatigue growth zone in Figure 8(b). Many tear dimples and microcracks are shown in Figure $8(\mathrm{e})$, which was the transition zone from the fatigue crack growth zone to the transient fracture zone. In the process of forming local microcracks, the joint between dimples was stretched or broken, which made the fracture crack expanded. With the increase in the number of cycles, the crack propagates to the thickness and width of the plate, which eventually led to the instantaneous fracture of the joint [25]. At the same time, the riveting leg and the lower plate and the upper plate and the lower plate produced severe vibration wear, which made the lower plate break, leading to the joint failure.

3.4.2. Failure Mechanism of AA40 Joints. Figure 9 shows the fracture morphology of AA40 group No. 8 joint. Figure 9(b) shows the morphology of zone 1, which showed the characteristics of early fatigue bands and a large amount 


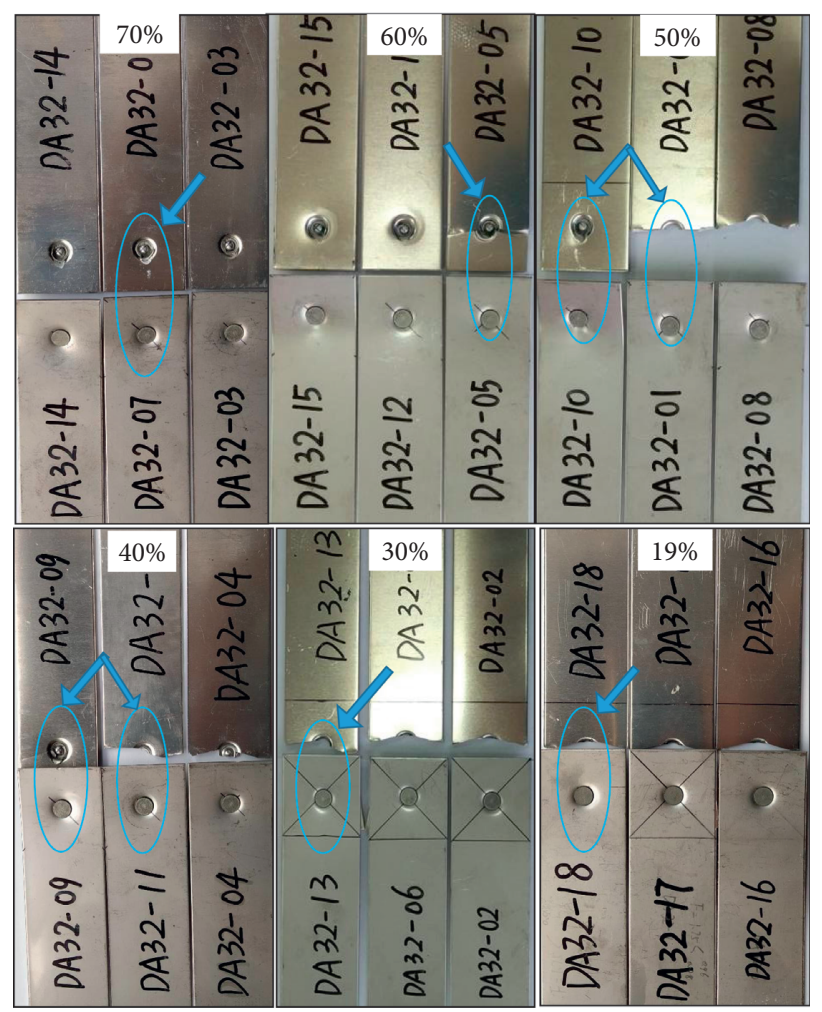

(a)

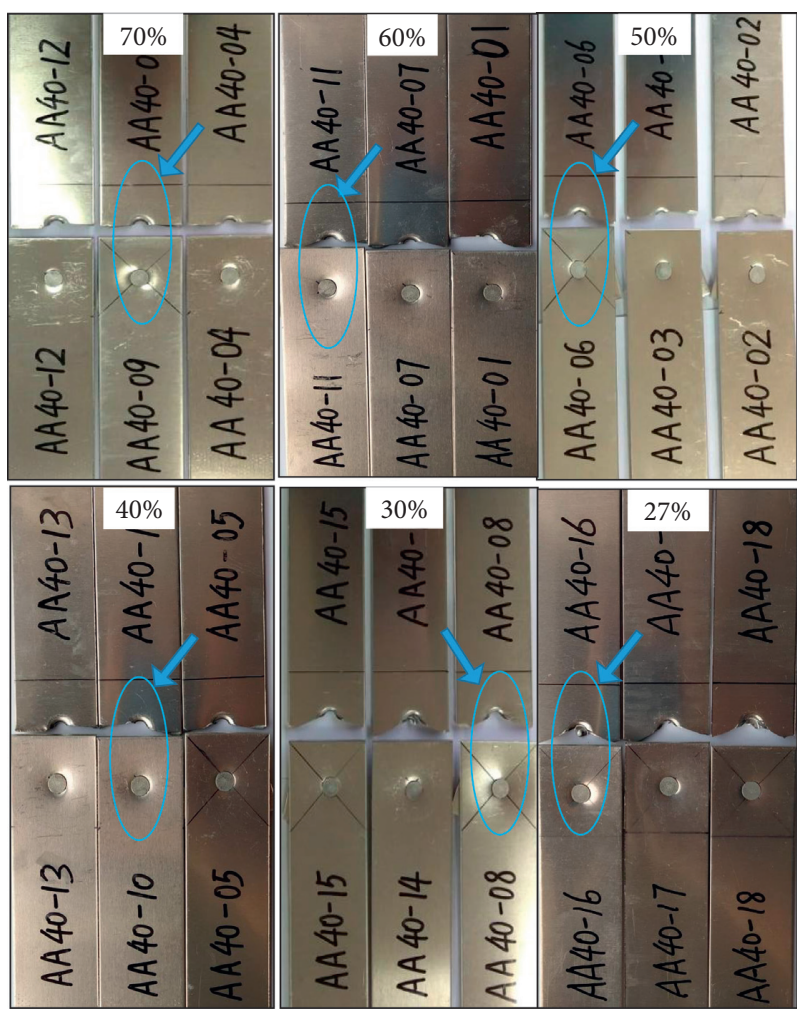

(b)

FIGURE 6: Fatigue failure samples of SPR joints: (a) failed DA32 samples; (b) failed AA40 samples.

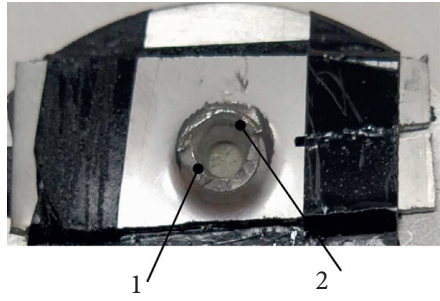

(a)

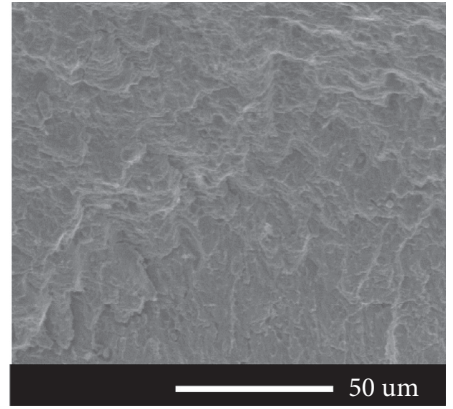

(b)

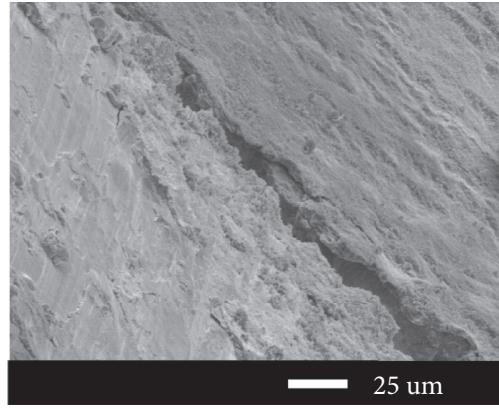

(c)

FiguRe 7: Fracture surface of the rivet for group DA32 No. 5: (a) macroscopic morphology of fatigue fracture; (b) 1 \# regional microstructure; (c) 2 \# regional microstructure [25].

of grinding debris. The fatigue strip was shallow in depth due to the severe friction between the rivet and the lower plate. The fatigue source was generated here. Figure 9(c) shows the morphology of zone 2 as cleavage step features with fatigue bands. Microcracks, micropores, and a small amount of debris can also be observed. Figure 9(d) shows that the microstructure of zone 3 was characterized by cleavage steps with fatigue bands. Microcracks, micropores, and a small amount of debris can also be observed. Compared with the morphology of zone 2, the crack here was wider and longer with less debris, which was the stable propagation region of the crack. As shown in Figure 9(e), the No. 4 area had a deep fatigue strip, a wide crack, and less debris, which was similar to the tire pressure mark, and was a significant feature of the crack propagation area. This was due to the cracks in the crack after cracking; the two opposite sides of the bulge in the repeated extrusion force formed traces. Compared with Figure $9(\mathrm{c})$, it can be seen that the fatigue source was closer to zone 2 , and the crack developed from the fatigue source region to the fatigue expansion region, resulting in the fracture of the lower plate. 
(a)
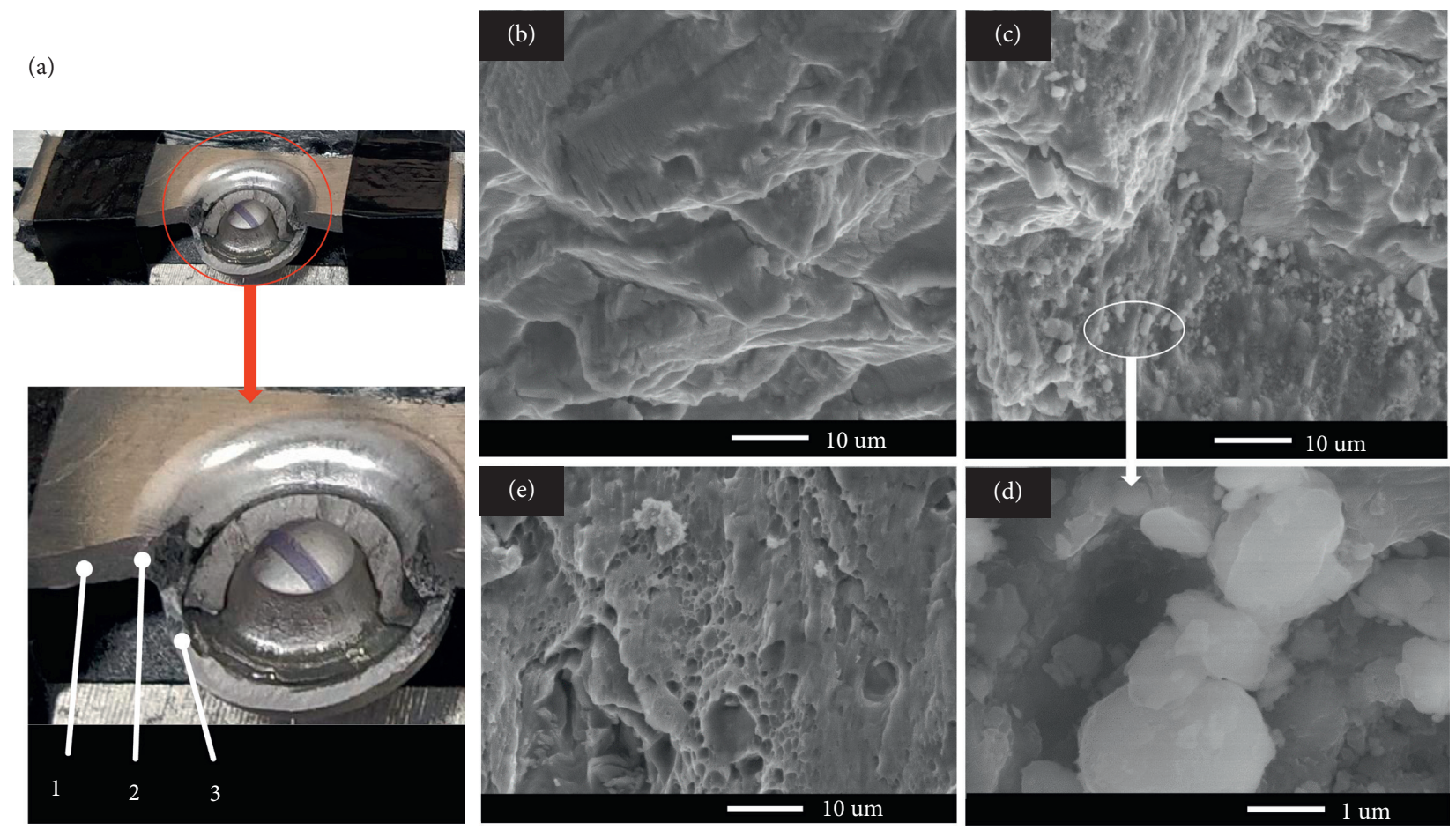

Figure 8: Fracture surface of the lower plate for group DA32 No. 5: (a) macroscopic morphology of fatigue fracture; (b) 1 \# regional microstructure; (c) 2 \# regional microstructure; (d) regional microstructure in figure (c); (e) 3 \# regional microstructure [25].

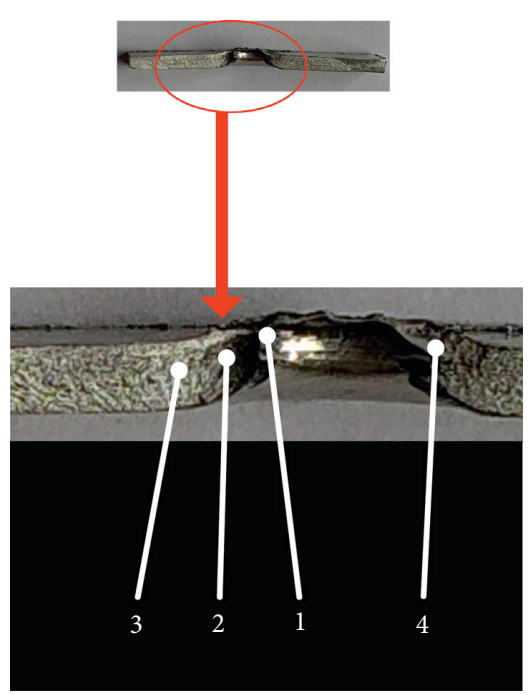

(a)

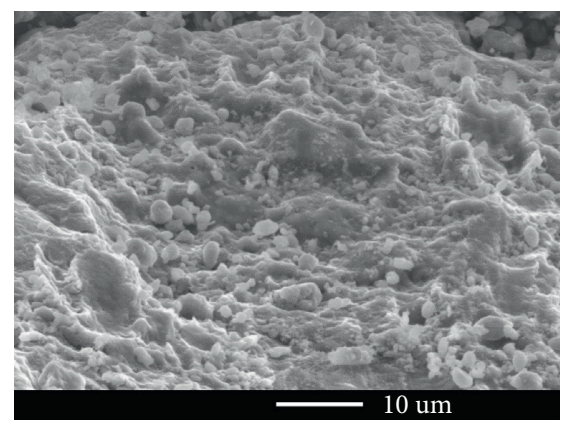

(b)

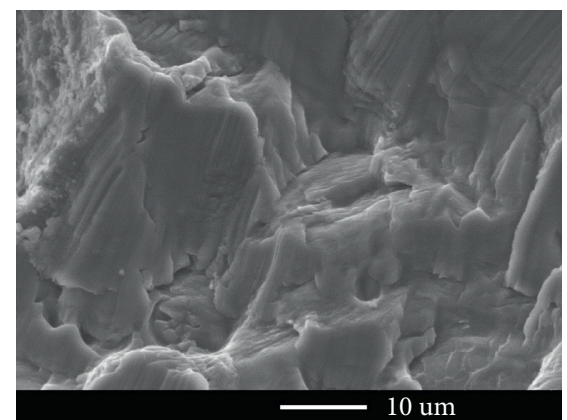

(e)

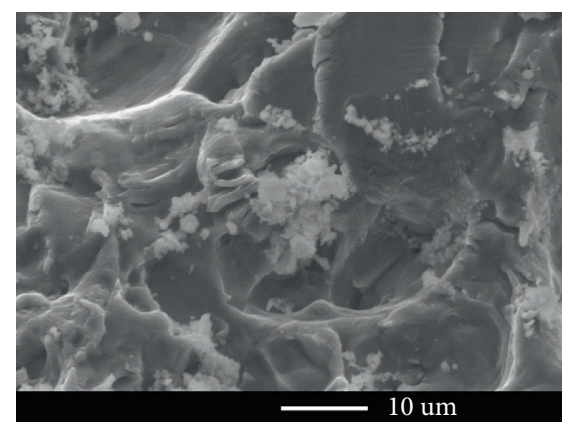

(c)

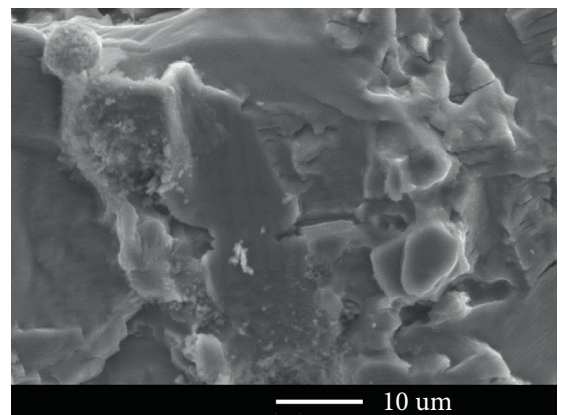

(d)

Figure 9: Fracture surface of the lower plate for group AA40 No. 8: (a) macroscopic morphology of fatigue fracture; (b) 1 \# regional microstructure; (c) 2 \# regional microstructure; (d) 3 \# regional microstructure; (e) 4 \# regional microstructure. 


\section{Conclusions}

In summary, two kinds of SPR joints with DP590 and AA6061 plates were fabricated. The forming quality, static and fatigue properties, and fatigue failure fracture of the SPR joints were reasearched, and the influence of plate types and thickness on fatigue strength and failure modes of SPR joints was surveyed as well. It is suggested that there is a positive correlation between the mechanical property of the SPR joint and its self-locking length. At the same fatigue load in medium or high load level, the DA32 joint is of a longer fatigue life than AA40. The fatigue failure mode changes from a single to multiple when the AA6061 aluminum alloy plate is replaced by dual-phase steel DP590. High-level loads tend to cause fracture failures around rivets of DA32 joints, while lower-level loads always result in fracture failures of the lower plate of DA32 orienting from the middle part of rivets to the edges of plates. Microstructural observation suggests fatigue quasi-brittle fracture characteristics of the rivets when fatigued, and severe fretting wear appears when the rivet is in a fatigue process. The fretting wear can cause the falling off of the surface coating of the rivet foot and an increase in the failure rate, which indicates an approach to prolong the fatigue life of the joints by reducing the friction and wear of the joints. This work may enrich the research on fatigue behavior of SPR joints and provide effective approaches to enhance the stability of SPR joints.

\section{Data Availability}

All data and models used to support the findings of this study are included within the article.

\section{Conflicts of Interest}

The authors declare that they have no conflicts of interest.

\section{Acknowledgments}

This research was supported by the National Natural Science Foundation of China (51875201).

\section{References}

[1] J. Zhang, X. He, and W. Ding, "Mechanical properties of selfpiercing riveted joint of carbon fiber composites and light alloy sheet," Ordnance Material Science and Engineering, vol. 41, no. 3, pp. 48-51, 2018.

[2] M. Carandente, R. J. Dashwood, I. G. Masters, and L. Han, "Improvements in numerical simulation of the SPR process using a thermo-mechanical finite element analysis," Journal of Materials Processing Technology, vol. 236, pp. 148-161, 2016.

[3] P.-C. Lin, J.-W. Lin, and G.-X. Li, "Clinching process for aluminum alloy and carbon fiber-reinforced thermoplastic sheets," International Journal of Advanced Manufacturing Technology, vol. 97, no. 1-4, pp. 529-541, 2018.

[4] S.-H. Lee, C.-J. Lee, K.-H. Lee, J.-M. Lee, B.-M. Kim, and D.-C. Ko, "Influence of tool shape on hole clinching for carbon fiber-reinforced plastic and SPRC440," Advances in Mechanical Engineering, vol. 6, Article ID 810864, 2015.
[5] Z. Huang, "Developments of sheet joining," Forging \& $t$ Technology, vol. 28, no. 4, pp. 119-122, 2006.

[6] B. Xing, X. He, Y. Wang, and C. Deng, "Fatigue properties and failure mechanisms of self-piercing riveted joints in aluminium alloy," Transactions of the China Welding Institute, vol. 6, pp. 50-54, 2016.

[7] W. Yan, Z. Xie, C. Yu, L. Song, and H. He, "Experimental investigation and design method for the shear strength of selfpiercing rivet connections in thin-walled steel structures," Journal of Constructional Steel Research, vol. 133, pp. 231-240, 2017.

[8] L. Huang, H. Guo, Y. Shi, S. Huang, and X. Su, "Fatigue behavior and modeling of self-piercing riveted joints in aluminum alloy 6111," International Journal of Fatigue, vol. 100, pp. 274-284, 2017.

[9] M. Fu and P. K. Mallick, "Effect of process variables on the static and fatigue properties of self-piercing riveted joints in aluminum alloy 5754," SAE Technical Paper Series, vol. 1, 2001.

[10] W. S. Miller, L. Zhuang, J. Bottema et al., "Recent development in aluminium alloys for the automotive industry," Materials Science and Engineering: A, vol. 280, no. 1, pp. 37-49, 2000.

[11] X. Sun and M. A. Khaleel, "Strength estimation of selfpiercing rivets using lower bound limit load analysis," Science and Technology of Welding \& Joining, vol. 10, no. 5, pp. 624-635, 2005.

[12] Z. Huang, S. Xue, J. Lai, L. Xia, and J. Zhan, "Self-piercing riveting with inner flange pipe rivet," Procedia Engineering, vol. 81, pp. 2042-2047, 2014.

[13] X. Liu, L. Zhang, S. Li, S. Wan, and W. Liu, "Finite element numer ical simulation of self- pierce riveting," Automobile Technology, vol. 12, pp. 42-45, 2006.

[14] S. Wan, S. Hu, S. Li, L. Zhang, and X. Liu, "Process parameters and joint evaluation of self piercing riveting with half hollow rivets," Journal of Tianjin University, vol. 4, pp. 494-498, 2007.

[15] H. M. Rao, J. Kang, G. Huff, and K. Avery, "Impact of specimen configuration on fatigue properties of self-piercing riveted aluminum to carbon fiber reinforced polymer composite," International Journal of Fatigue, vol. 113, pp. 11-22, 2018.

[16] Y. Liu and W. Zhuang, "Self-piercing riveted-bonded hybrid joining of carbon fibre reinforced polymers and aluminium alloy sheets," Thin-Walled Structures, vol. 144, Article ID 106340, 2019.

[17] H. Jiang, L. Sun, J. Liang, G. Li, and J. Cui, "Shear failure behavior of cfrp/al and steel/al electromagnetic self-piercing riveted joints subject to high-speed loading," Composite Structures, vol. 230, Article ID 111500, 2019.

[18] Y. K. Chen, L. Han, A. Chrysanthou, and J. M. O'Sullivan, "Fretting wear in self-piercing riveted aluminium alloy sheet," Wear, vol. 255, no. 7-12, pp. 1463-1470, 2003.

[19] Z. Huang, T. Song, and J. Lai, "Fatigue property and failure mechanism of self piercing riveted joints of TA1 titanium alloy," Transactions of the China Welding Institute, vol. 40, no. 3, pp. 162-163, 2019.

[20] L. Zhao, X. He, B. Xing, X. Zhang, C. Deng, and Y. Liu, "Fracture mechanism of titanium sheet self-piercing riveted joints," Thin-Walled Structures, vol. 144, Article ID 106353, 2019.

[21] W. Jin, B. Xing, X. He, K. Zeng, and K. Yu, "Failure behavior analysis of self-piercing riveted joints of steel-aluminum dissimilar metal under acidic environment," Ordnance 
Material Science and Engineering, vol. 42, no. 1, pp. 123-126, 2019.

[22] H. Jiang, Y. Liao, S. Gao, G. Li, and J. Cui, "Comparative study on joining quality of electromagnetic driven self-piecing riveting, adhesive and hybrid joints for al/steel structure," Thin-Walled Structures, vol. 164, Article ID 107903, 2021.

[23] W. Ding, X. He, J. Liu, J. Lu, and W. Wenjie, "Performance of self-pierce riveting based on carbon fiber reinforced polymerAA5052 aluminum alloy three-layer sheets," Science Technology and Engineering, vol. 18, no. 25, pp. 143-147, 2018.

[24] X. Zhang, X. He, B. Xing, W. Wei, and J. Lu, "Pre-holed selfpiercing riveting of carbon fibre reinforced polymer laminates and commercially pure titanium sheets," Journal of Materials Processing Technology, vol. 279, Article ID 116550, 2020.

[25] Z. Huang, Y. Jia, and J. Lai, "Fatigue characteristics and failure mechanism of self-piercing riveted joints of DP590 and AA6061 plates," in Forming the Future. The Minerals, Metals \& Materials Series, G. Daehn, J. Cao, B. Kinsey, E. Tekkaya, A. Vivek, and Y. Yoshida, Eds., Springer, Cham, Switzerland, 2021.

[26] H. Jiang, T. Luo, G. Li, X. Zhang, and J. Cui, "Fatigue life assessment of electromagnetic riveted carbon fiber reinforce plastic/aluminum alloy lap joints using weibull distribution," International Journal of Fatigue, vol. 105, pp. 180-189, 2017.

[27] Z. Gao, H. Fu, and S.-N. Liang Meixun, "curve fitting method," Journal of Beijing Institute of Aeronautics and Astronautics, vol. 1, pp. 115-119, 1987.

[28] Y. Liu, X. He, B. Xing, C. Deng, and X. Zhang, "Fatigue properties and failure mechanisms of self-piercing riveted joints in metal foam sandwich structures," Materials Reports, vol. 32, no. 14, pp. 2431-2436, 2018. 